\title{
An investigation progress toward Be-based ablator materials for the inertial confinement fusion
}

\author{
Bingchi Luo ${ }^{1,2}$, Jiqiang Zhang ${ }^{1}$, Yudan $\mathrm{He}^{1}$, Long Chen ${ }^{1}$, Jiangshan Luo ${ }^{1,2}, \mathrm{Kai} \mathrm{Li}^{1,2}$, and Weidong $\mathrm{Wu}^{1,2}$ \\ ${ }^{1}$ Research Center of Laser Fusion, China Academy of Engineering Physics, Mianyang 621900, China \\ ${ }^{2}$ Science and Technology on Plasma Physics Laboratory, Mianyang 621900, China \\ (Received 18 September 2016; revised 24 December 2016; accepted 7 February 2017)
}

\begin{abstract}
The Be-based materials with many particular properties lead to an important research subject. The investigation progresses in the fabrication technologies are introduced here, including main three kinds of Be-based materials, such as $\mathrm{Be}-\mathrm{Cu}$ capsule, $\mathrm{Be}_{2} \mathrm{C}$ ablator and high-purity Be material. Compared with the pioneer workgroup on Be-based materials, the differences in $\mathrm{Be}-\mathrm{Cu}$ target fabrication were described, and a grain refinement technique by an active hydrogen reaction for $\mathrm{Be}$ coating was proposed uniquely. $\mathrm{Be}_{2} \mathrm{C}$ coatings were first prepared by the $\mathrm{DC}$ reactive magnetron sputtering with a high deposition rate $(\sim 300 \mathrm{~nm} / \mathrm{h})$. Pure polycrystalline $\mathrm{Be}_{2} \mathrm{C}$ films with uniform microstructures, smooth surface, high density $\left(\sim 2.2 \mathrm{~g} \cdot \mathrm{cm}^{3}\right)$ and good optical transparency were fabricated. In addition, the high-purity Be materials with metal impurities in a ppm magnitude were fabricated by the pyrolysis of organometallic Be.
\end{abstract}

Keywords: Be-based materials; $\mathrm{Be}-\mathrm{Cu}$ capsule; $\mathrm{Be}_{2} \mathrm{C}$ ablator; high purity

\section{Introduction}

Some properties of Be-based materials, such as nucleus property, physics property and ablation property cannot be substituted by any other metal materials ${ }^{[1-12]}$. In comparison to the conventional $\mathrm{CH}$ ablator, Be-based materials are the best inertial confinement fusion (ICF) ablator due to their low x-ray opacity, high density, high thermal conductivity, as well as having the highest mass ablation rate at every temperature and providing more ablative stabilization ${ }^{[1-4]}$. The lower opacity allows the $\mathrm{x}$-rays to penetrate deeper into the Be shell and absorb more energy. The higher density allows more ablative material for a given shell. The higher thermal conductivity is advantageous of the temperature uniformity and forming the symmetrical DT ice layer. In addition, the higher ablation velocities allow implosion of more fuel, and the ablative stabilization reduces the effect of hydrodynamic instabilities during implosion ${ }^{[4]}$. As for the promising ignition targets, $\mathrm{Be}-\mathrm{Cu}, \mathrm{Be}_{2} \mathrm{C}$ and high-purity $\mathrm{Be}$ materials have aroused special research interest in the field of $\mathrm{ICF}^{[7,8]}$.

As for one Be-based material, $\mathrm{Be}-\mathrm{Cu}$ capsule, has been studied by the workgroups of Lawrence Livermore National Laboratory (LLNL), Los Alamos National Laboratory

Correspondence to: W. D. Wu, Research Center of Laser Fusion, China Academy of Engineering Physics, No. 64, Mianshan Road, Mianyang 621900, China. Email: wuweidongding@163.com
(LANL) and General Atomics (GA). The investigation contents mainly focus on the grain size, microstructure homogeneity, thickness uniformity, surface defect, surface smoothness, density, root-mean-square (RMS) surface roughness, stepwise dopant, as well as capsule metrology and characterization ${ }^{[9-11]}$. During the Be-based coating growth, the $\mathrm{Be}$ atoms array in the form of hexagonalclose-packed (hcp) structure, and the crystal grains grow along $c$-axis orientation. The Be coatings are mainly characterized by a coarsening columnar grain, and display a strong anisotropy characteristics ${ }^{[12-15]}$. These disadvantages weaken the mechanical property and affect ablation characteristics for Be-based materials; thus, a grain refinement method should be developed.

As for another Be-based material, $\mathrm{Be}_{2} \mathrm{C}$ ablator, is considered as an excellent potential target ablator because it combines the advantages of both hydrocarbon and $\mathrm{Be}$, and achieves a more balanced ablation performance ${ }^{[16,17]}$. It owns the lower atomic number $(Z=4.7)$, and the higher density $\left(\rho=2.4 \mathrm{~g} / \mathrm{cm}^{3}\right)$ and mechanical strength than many hydrocarbons ${ }^{[18,19]}$. Xie et al. prepared $\mathrm{Be}_{2} \mathrm{C}$ films for the first time by plasma polymerization of diethyl-beryllium. However, it was difficult to control the ratio of Be to C. Meantime, Shih et al. developed radio frequency $(\mathrm{RF})$ reactive magnetron sputtering for depositing $\mathrm{Be}_{2} \mathrm{C}$ coatings, which has a low deposition rate $(<56 \mathrm{~nm} / \mathrm{h})$. These shortcomings limited the development of $\mathrm{Be}_{2} \mathrm{C}$ 
coating fabrication ${ }^{[17,20-23]}$. Lately, DC reactive magnetron sputtering was adopted and provided a new promising method to prepare $\mathrm{Be}_{2} \mathrm{C}$ coatings ${ }^{[24]}$.

As a Be material, especially a high-purity $\mathrm{Be}$, it is indispensable for a raw material during the fabrication of $\mathrm{Be}$ based materials. In the design of Be-based materials, the impurity contained is inversely proportional to the square of atomic number $(Z)^{[25,26]}$ because of being sensitive to the implosion process. The larger the $Z$ is, the lower the impurity is. Usually, the impurity in Be materials is mainly $\mathrm{O}, \mathrm{C}, \mathrm{Fe}, \mathrm{Al}, \mathrm{Si}$, etc, which is associated with the Be ore compositions. The S-65C Be materials with a purity of 99.54 wt.\% was first produced by Brush Wellman in $1997^{[27]}$, and the main impurity included $0.6 \% \mathrm{BeO}, 0.012 \%$ C, $620 \mathrm{ppm} \mathrm{Fe}, 185 \mathrm{ppm} \mathrm{Al}, 160 \mathrm{ppm} \mathrm{Si}$ and $130 \mathrm{ppm}$ Ni. Subsequently, the Materion Corporation (previous Brush Wellman) announced the ultrahigh purity Be material with $99.99 \%$ in 2011. It is very regretful that the Be purification technique, in particular ultrahigh purity $\mathrm{Be}$, is scarcely reported because of technique secrecy. Although some research institutions reported that they successfully purified Be via some technology ${ }^{[28,29]}$, such as vacuum distillation, zone melting, electrotransport processing and so on, they did not give the experimental details, impurity compositions and level.

The objective of this paper is to introduce the fabrication technology of Be-based materials, including $\mathrm{Be}-\mathrm{Cu}$ capsule, $\mathrm{Be}_{2} \mathrm{C}$ ablator and high-purity Be material, as well as their research progresses, and then analyze the difference between ours and pioneer workgroup's. In addition, a new grain refinement way by an active hydrogen reaction for strong anisotropic Be coating, an effective deposition method for preparing uniform $\mathrm{Be}_{2} \mathrm{C}$ coatings with a smooth surface, and a pyrolytic technology for Be material purification have been reported here.

\section{Be-Cu capsule}

\subsection{Preparation principle of $\mathrm{Be}-\mathrm{Cu}$ capsule}

There are two kinds of technologies to fabricate the $\mathrm{Be}-\mathrm{Cu}$ capsule, the physical vapor deposition (PVD) and chemical vapor deposition (CVD). At present, the main technology is the magnetron sputtering, which belongs to PVD methods. The magnetron can generate plasma by the glow discharge on its surface. The ionized gas atoms (in our case Ar) are accelerated by an electric field, and then collide with a target material of sputtering source. Be atoms or $\mathrm{Cu}$ atoms would be ejected from the target surface and deposit onto the substrate to form the coating. For a $\mathrm{Be}-\mathrm{Cu}$ capsule fabrication, the substrate requires a spherical mandrel, such as poly(alpha-methylstyrene) (PAMS), $\mathrm{Si}, \mathrm{Ni}$ and $\mathrm{Fe}$, as a template onto which the metal is deposited. In order to improve the thickness uniformity, a bounce pan needs to be used, which is to provide a nearly random motion. The bounce pan is usually agitated by the knock, rotating, shake, as well as their combination mode during the coating.

There are many advantages for magnetron sputtering technique to fabricate the Be capsule. First, the target material can be fixed at arbitrary directions. The particle beam flux is from up to down, which is convenient to fabricate the Be capsule coupling the bounce pan. Second, there is small substrate thermal effect. When the sputtering power is lower than $120 \mathrm{~W}$, the substrate temperature is less than $120^{\circ} \mathrm{C}$ in our experiment. Accordingly, the plastic mandrels can be easy for selection, which is favorable to pyrolytic removal in the latter. Third, the incident particle energy during sputtering is about several to tens of electron volts, and the coating has a high density.

\subsection{Dopant rule in Be capsule}

The Be capsule used as ablator and DT fuel container usually needs to dope other element, which mostly is doped middle $Z$. Its aim is to adjust the opacity, which keep x-ray flux and suprathermal electrons from preheating the inner DT ice layer, and ensure the hot spot with a low entropy compress before implosion. Moreover, the graded $\mathrm{Cu}$-doped Be has less sensitivity to perturbations, which helps to reduce Rayleigh-Taylor instability during implosion ${ }^{[11,19,26,30]}$. Due to the small $\mathrm{Be}$ atom radius, most elements are fully immiscible with Be each other. The doped elements in Be need to consider its solid solubility. According to the binary alloy phase diagrams ${ }^{[31]}$, there exist only four species $(Z<50)$, such as $\mathrm{Co}, \mathrm{Ni}, \mathrm{Cu}$ and $\mathrm{Pd}$, that solid solubility is larger than $1 \%$. The solid solubility of $\mathrm{Cu}$ in $\mathrm{Be}, 9.5$ at.\%, is the largest than other. Therefore, the $\mathrm{Cu}$ element is first selected as dopant in Be for the National Ignition Facility (NIF) targets design, which can leave more margins to upgrade target. Previously, the $\mathrm{Cu}$ dopant concentration in $\mathrm{Be}$ is designed as 0.7 at.\% in $\operatorname{Rev} 0^{[30,32]}$, while the level of $\mathrm{Cu}$ dopant in $\mathrm{Rev} 6 \mathrm{Be}-\mathrm{Cu}$ capsule designed by Wilson et al. ${ }^{[1,2]}$ has increased to 3.0 at.\%. Obviously, the target development would be limited if other elements were selected.

\subsection{Progress on Be-Cu capsule}

The $\mathrm{Cu}$-doped Be capsules were prepared by DC magnetron sputtering using the separate $\mathrm{Cu}$ and $\mathrm{Be}$ sources onto about $1.2 \mathrm{~mm}$ diameter PAMS spherical mandrels. Four round magnetrons were equipped with a Be target of $76.2 \mathrm{~mm}$ in diameter, fixed symmetrically around the center of the chamber, where one $50.8 \mathrm{~mm} \mathrm{Cu}$ magnetron sputter source was positioned. The magnetrons point down toward a bounce pan that holds the samples. The base pressure was typically $2 \times 10^{-6} \mathrm{~Pa}$, and the sputtering pressure is in $0.1-$ 1.0 $\mathrm{Pa} \mathrm{Ar}$ environment. The distance between the substrate 


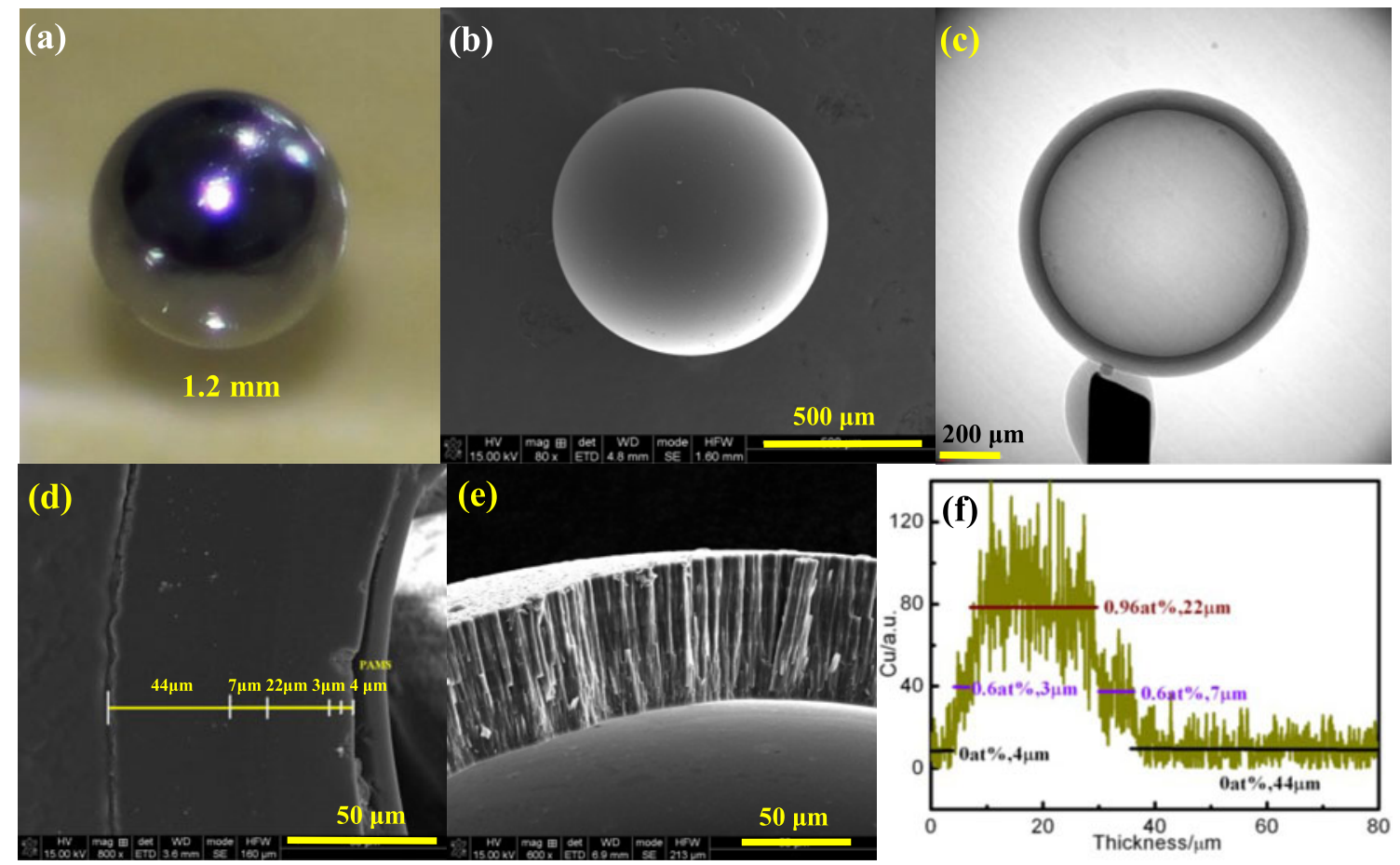

Figure 1. Be-Cu capsule. (a) Optical microscope image, (b) SEM image, (c) micro-CT image, (d) polished cross-section morphology, (e) cross-section morphology, (f) $\mathrm{Cu}$ dopant distribution at cross-section.

and Be target is $90 \mathrm{~mm}$, which is not in good agreement with the $\mathrm{Cu}$ target to substrate distance of $300 \mathrm{~mm}$. The four $\mathrm{Be}$ guns are operated at the range of $60-120 \mathrm{~W}$, while one $\mathrm{Cu}$ gun is at $10-30 \mathrm{~W}$. The coating rates are $0.3-0.42 \mu \mathrm{m} / \mathrm{h}$ at the situation.

The specifications of $\mathrm{Be}-\mathrm{Cu}$ capsule prepared by the sputtering method in our experiment: the capsule diameter is $1.2 \mathrm{~mm}$, RMS roughness $85 \mathrm{~nm}$, average deviation of wall thickness $\pm 1.5 \mu \mathrm{m}$, the $\mathrm{Cu}$ dopant in the concentration range of 0.6 at.\%-0.96 at.\%, starting from the inside of Be shell, the thickness for each shell layer is $4,3,22,7$ and $44 \mu \mathrm{m}$, while the $\mathrm{Cu}$ is distributed as 0, 0.6 at.\%, 0.96 at.\%, 0.6 at.\% and 0 , as shown in Figure 1. Further, the impurity and composition is detected by the inductively coupled plasmamass spectrometry (ICP-MS) method, including 0.003 at.\% $\mathrm{Al}, 0.04$ at. \% Si, 0.025 at.\% Mn, 0.97 at.\% $\mathrm{Fe}$ and 0.058 at.\% $\mathrm{Ni}$. Both $\mathrm{O}$ and $\mathrm{C}$ elements are quantitatively analyzed by energy dispersive $\mathrm{x}$-ray spectrometer (EDS) at 1.3 at.\% and 4.5 at. $\%$, respectively.

Figure 1(a) presents the optical microscope images of $\mathrm{Be}-$ $\mathrm{Cu}$ capsule with $1.2 \mathrm{~mm}$ diameter, and the polished capsule surface looks smooth and glistening. Figure 1(b) reveals the scanning electron microscope (SEM) image of $\mathrm{Be}-\mathrm{Cu}$ capsule. Figure 1(c) gives the micro-computed tomography (CT) image of $\mathrm{Be}-\mathrm{Cu}$ capsule. The shell thickness can be clearly observed and the difference of gray value along radial direction indicates the dopant level change. Figure 1(d) gives the polished cross-section of $\mathrm{Be}-\mathrm{Cu}$ capsule, and each dopant shell layer can be basically distinguished. Figure 1(e) gives the cross-section microstructure of $\mathrm{Be}-\mathrm{Cu}$ capsule, which is characterized by the columnar grain. Figure 1(f) gives the EDS pattern and the $\mathrm{Cu}$ distribution along the radial direction, which is quantitatively determined via the ICP-MS scaling.

In order to further compare and analyze, the Rev 5 specifications for $\mathrm{Be}-\mathrm{Cu}$ capsule $^{[26]}$ designed and fabricated by the LLNL workgroup are given. The $\mathrm{Be}-\mathrm{Cu}$ capsules are made of inner and outer layers of pure $\mathrm{Be}$ with three thin intermediate layers of $\mathrm{Be}$ with a $\mathrm{Cu}$ dopant. The capsule diameter is $2.36 \mathrm{~mm}$, wall thickness deviation $\pm 1.5 \mu \mathrm{m}$, RMS roughness $20 \mathrm{~nm}$, the $\mathrm{Cu}$ dopant in $\mathrm{Be}$, the concentration deviation \pm 0.1 at.\%. Starting from the inside of Be shell, the thickness for each shell layer is $5,4,23,8$ and $118 \mu \mathrm{m}$, respectively. Be impurities can be controlled at $\mathrm{O}<$ 0.4 at. $\%, \mathrm{Ar}<0.25$ at.\%, $\mathrm{C}<0.005$ at.\%, $\mathrm{Al}<0.01$ at.\%, $\mathrm{Si}<0.005$ at.\%, $\mathrm{Mn}<0.00015$ at. $\%, \mathrm{Fe}<0.005$ at. $\%$ and $\mathrm{Ni}<0.001$ at. $\%$.

Some differences on the fabrication technique of $\mathrm{Be}-$ $\mathrm{Cu}$ capsule still exist between LLNL workgroup and ours. First, our Be capsule has a small diameter of $1.2 \mathrm{~mm}$, which is limited by the mandrel preparation technology. The PAMS mandrels with $\sim 2.0 \mathrm{~mm}$ diameter cannot be produced at present. Second, the surface roughness of $\mathrm{Be}-$ $\mathrm{Cu}$ capsule cannot still arrive at $20 \mathrm{~nm}$, and the capsule polishing technology needs to be further studied. Third, the impurity elements listed in Rev 5 were also detected and they had high concentrations in $\mathrm{Be}-\mathrm{Cu}$ capsule, especially $\mathrm{O}$. 

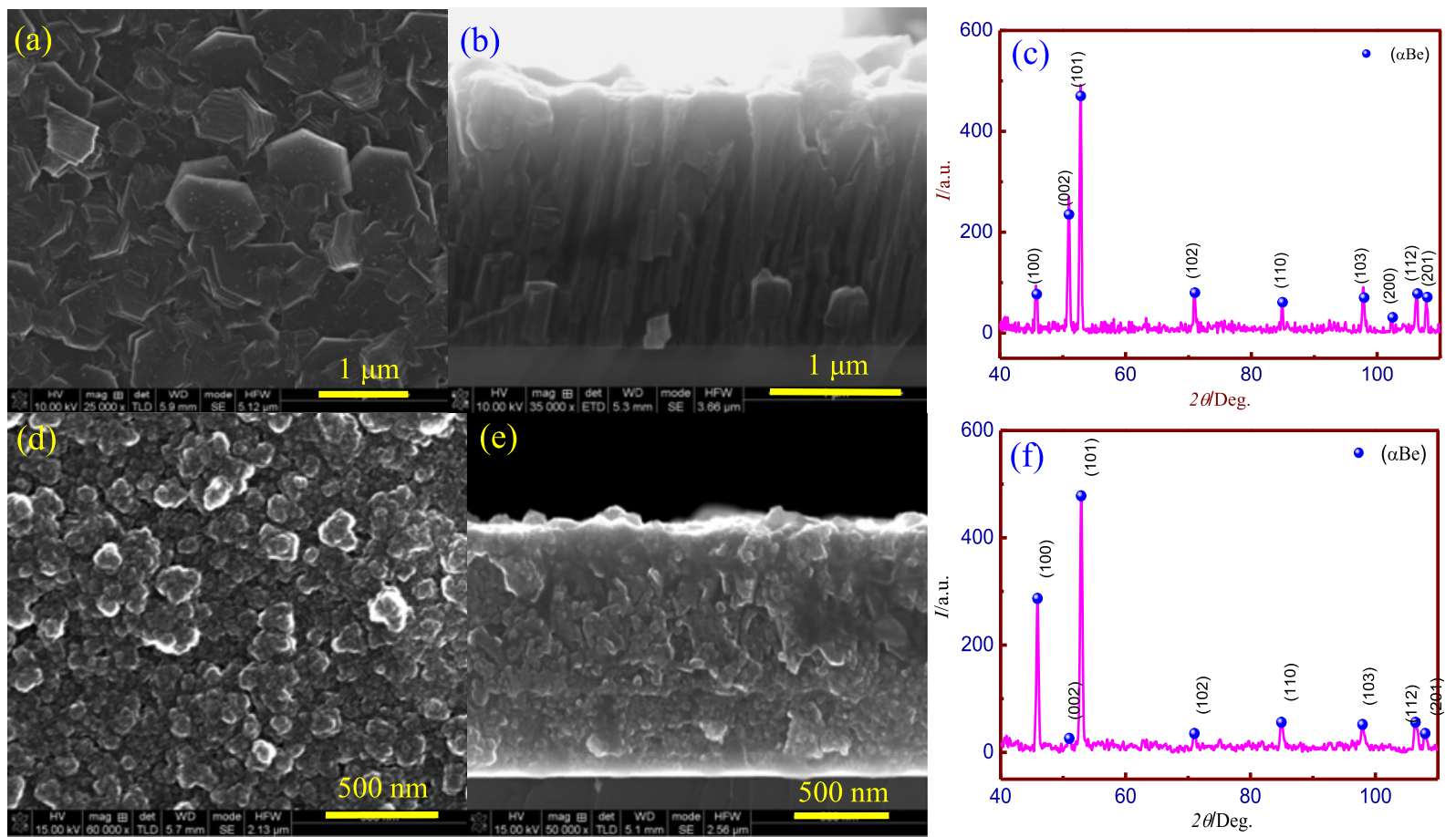

Figure 2. Be coating morphologies. (a), (b) and (c) surface microstructure, cross-section microstructure and XRD pattern of Be coating prepared by thermal evaporation, (d), (e) and (f) surface microstructure, cross-section microstructure and XRD pattern of Be coating prepared by reactive evaporation.

The main reason is that the purity of Be targets is low, about 99 at.\%. A high-purity Be target, which is difficult to fabricate and purchase, needs to be used during sputtering. Fourth, the target fabrication technology is still imperfect, and the investigation on drill hole and mandrel pyrolysis still remains to be done.

\subsection{Progress on Be grain refinement}

The Be capsule fabricated by anyone or any method is always characterized by a columnar grain with large diameter ${ }^{[33-37]}$, which is relevant closely to a hcp structure of Be. The lattice constant, $a=0.2286 \mathrm{~nm}, c=0.3584 \mathrm{~nm}$, and the ratio $c$ to $a$ is 1.568 , which is the lowest in all metals with hcp structure. Thus, the Be film is easy to grow along a preferential orientation and displays a strong anisotropy. The columnar grain reduces the Be capsule performance in the yield strength, fuel retention and ablation velocity, which is restricted in its development and application in the field of ICF. The nanocrystalline Be capsule can improve these capsule performances, which has aroused great research interest.

The Be coating is prepared by a reactive evaporation method $^{[38,39]}$. After a Be coating is deposited by a thermal evaporation and achieves a thickness, the $\mathrm{H}_{2}$ ionization source by RF fluxes into the vacuum chamber during the evaporation, which mixes into the $\mathrm{Be}$ atom beam and produces the $\mathrm{BeH}_{2}$. The amorphous $\mathrm{BeH}_{2}$ can interrupt the growth of $\mathrm{Be}$ columnar grain and achieves the $\mathrm{Be}$ grain refinement. The base pressure of reactive evaporation equipment was typically $5 \times 10^{-6} \mathrm{~Pa}$, and the distance of source to substrate is about $150 \mathrm{~mm}$. One condition of Be coating fabrication is the evaporation temperature of $1100^{\circ} \mathrm{C}$, the deposition time of $40 \mathrm{~min}$, and the deposition rate of $5.5 \mathrm{~nm} / \mathrm{min}$. Another condition of $\mathrm{BeH}_{2}$ coating fabrication is the evaporation temperature of $1100^{\circ} \mathrm{C}$, the RF power of $200 \mathrm{~W}$, the reflected power less than $20 \mathrm{~W}$, the $\mathrm{H}_{2}$ gas flow of $20 \mathrm{sccm}$, work pressure of $0.25 \mathrm{~Pa}$, deposition time of $5 \mathrm{~min}$, and the deposition rate of $1.7 \mathrm{~nm} / \mathrm{min}$. Both conditions are alternant to be carried out, and the experimental results are plotted in Figure 2.

Figures 2(a), (b) and (c) show the surface microstructure, cross-section microstructure and x-ray diffraction (XRD) pattern of Be coating prepared by thermal evaporation. The Be coating is characterized by a hexagonal sheet grain with an average diameter of $510 \mathrm{~nm}$, while the cross-section microstructure displays the parallel columnar grain each other. Figures 2(d), (e) and (f) show the surface microstructure, cross-section microstructure and XRD pattern of Be coating prepared by reactive evaporation. Although the Be coating consists of a $(\alpha-\mathrm{Be})$ phase, the growth morphologies are different each other. Here, the surface morphology looks very similar to the cross-section morphology comprised by the fine grain with an average diameter of $45 \mathrm{~nm}$. The Be columnar grain in the cross-section is interrupted by the chemical reaction of an active hydrogen with $\mathrm{Be}$ atom, and the produced amorphous $\mathrm{BeH}_{2}$ film with a few nanometer thickness can interrupt the Be columnar grain 


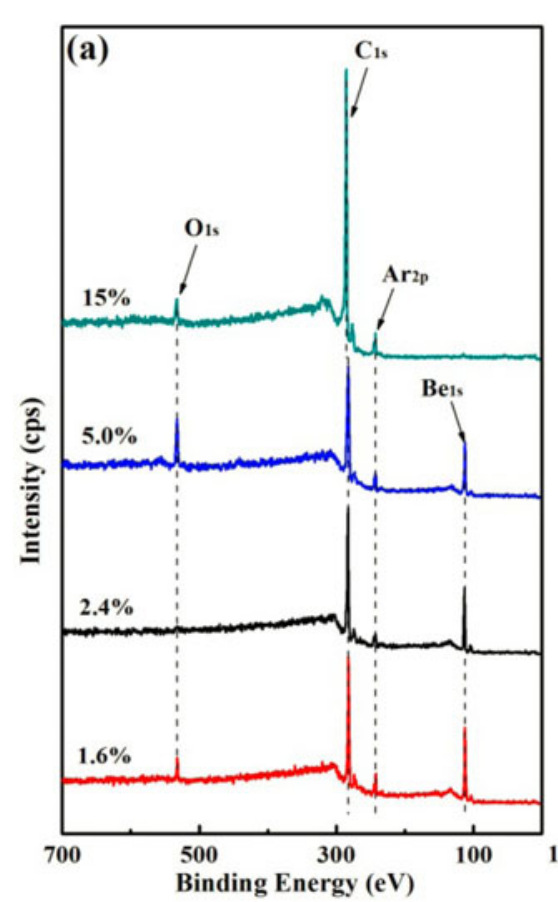

2600

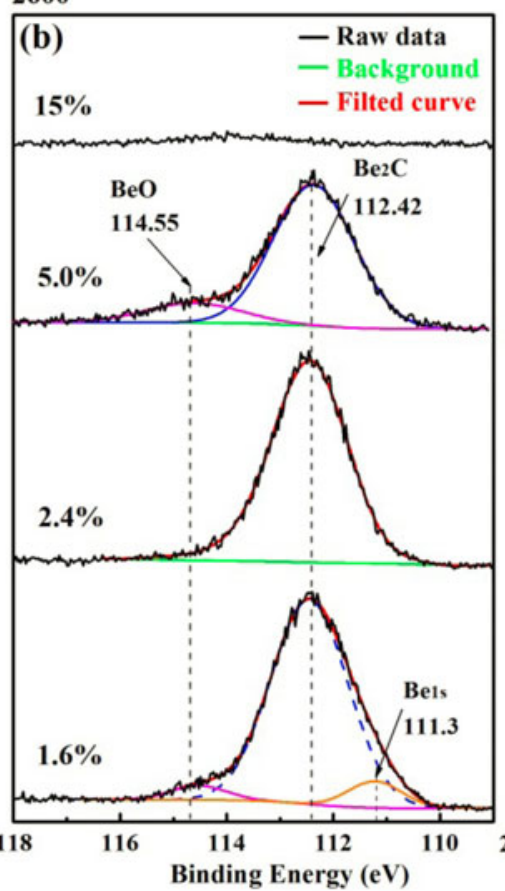

7200

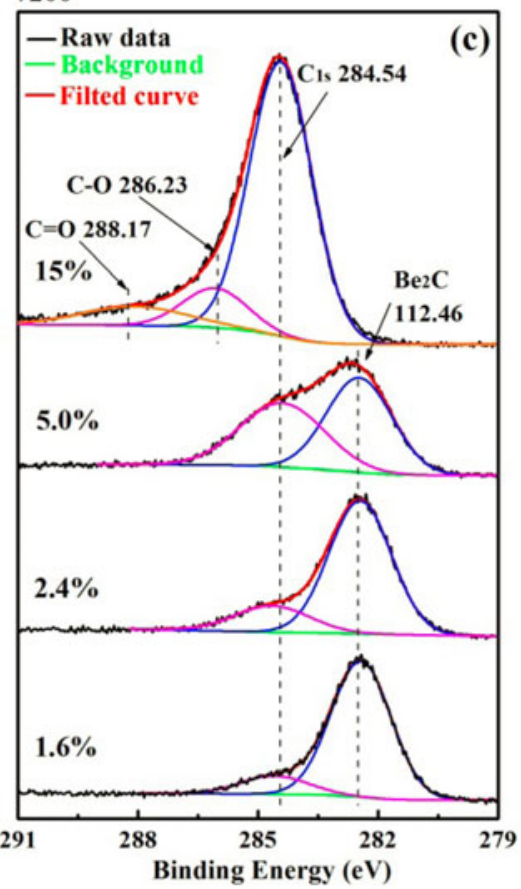

Figure 3. XPS spectra for films prepared at different $\mathrm{CH}_{4}-\mathrm{Ar}$ ratios after $30 \mathrm{~min} \mathrm{Ar}^{+}$etching survey spectrum (a), deconvolution of Be1s peaks (b) and deconvolution of $\mathrm{C} 1 \mathrm{~s}$ peaks (c).

growth. At present, the investigation on grain refinement of Be coating is still scarce, and has a little effect. The active hydrogen reaction method can offer new prospects to achieve the grain refinement for Be coating.

\section{3. $\mathrm{Be}_{2} \mathrm{C}$ ablators}

\subsection{Fabrication principle of $\mathrm{Be}_{2} \mathrm{C}$}

$\mathrm{Be}_{2} \mathrm{C}$ ablators were prepared by $\mathrm{DC}$ reactive magnetron sputtering of $\mathrm{Be}$ target under argon-methane mixture plasma ${ }^{[24]}$. Argon and methane are ionized by the glow discharge. Then, Ar ions were accelerated by high voltage electric field and impinged the target surface. The sputtered target atoms react with the ionized reaction gas $\left(\mathrm{CH}_{3}^{+}\right.$, $\mathrm{CH}_{2}^{2+}$, etc) and deposit onto the substrate to form thin films. Evidently, the target surface atoms also react with the ionized gases and form a compound layer, which will result in the target poisoning. During the sputtering, the poisoning effect can be controlled by optimizing the sputtering chamber and the reactive gas influx mode ${ }^{[24]}$.

\subsection{Progress on $\mathrm{Be}_{2} \mathrm{C}$ ablators}

In the present work, first, the process conditions were optimized to obtain pure polycrystalline $\mathrm{Be}_{2} \mathrm{C}$ films. Second, the properties of $\mathrm{Be}_{2} \mathrm{C}$ films were characterized to confirm its outstanding performance related to ICF application.

\subsection{1. $\mathrm{Be}_{2} \mathrm{C}$ composition and crystallinity optimization}

Figure 3 shows the variation of composition as a function of the $\mathrm{CH}_{4}-\mathrm{Ar}$ ratio, as given by $\mathrm{x}$-ray photoelectron spectroscopy (XPS) spectrum. It is found that the Be content decreases, while the $\mathrm{C}$ content increases gradually with the increasing $\mathrm{CH}_{4}-\mathrm{Ar}$ ratios. The pure hydrocarbon films will be formed when the $\mathrm{CH}_{4}-\mathrm{Ar}$ ratio exceeds the critical value. Similarly, the Be content in the films increases with the increase of sputtering power (not shown). Co-regulation of flow ratio and sputtering power is necessary for the preparation of pure $\mathrm{Be}_{2} \mathrm{C}$ films. The purest $\mathrm{Be}_{2} \mathrm{C}$ films have been obtained when the $\mathrm{CH}_{4}-\mathrm{Ar}$ ratio is $10 \%$ and sputtering power maintains at $150 \mathrm{~W}$.

Figures 4(a) and (b) give the typical high-resolution transmission electron microscope (TEM) image of $\mathrm{Be}_{2} \mathrm{C}$ film deposited at room temperature and typical XRD pattern of film grown at $600{ }^{\circ} \mathrm{C}$, respectively. $\mathrm{Be}_{2} \mathrm{C}$ films without in situ annealing exhibit a nanocrystalline composite structure and cannot be detected by XRD. Films grown at high temperature show obvious diffraction peaks similar to the standard $\mathrm{Be}_{2} \mathrm{C}$ powder diffraction card (PDF-33-0191) ${ }^{[40]}$, which indicate the films are mainly composed of polycrystalline particles without preferential orientation.

Thus, it can be concluded that: in the reactive sputtering process, the flow ratios and sputtering power mainly affect the compositions, and the substrate temperature influenced the crystallinity of the $\mathrm{Be}_{2} \mathrm{C}$ films. 
(a)

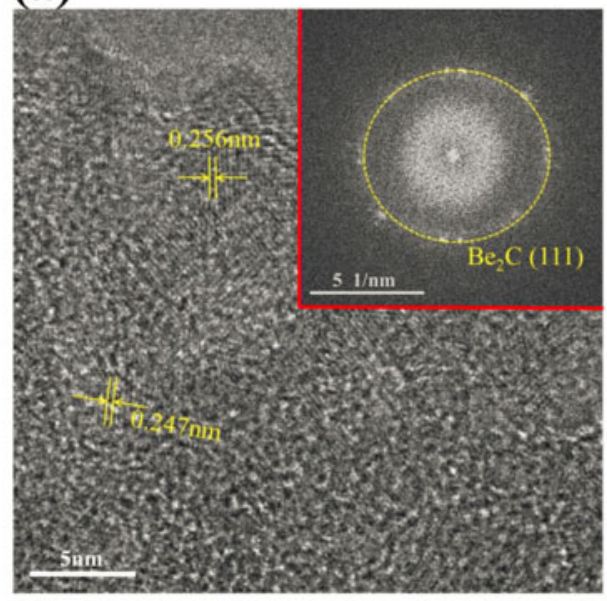

(b)

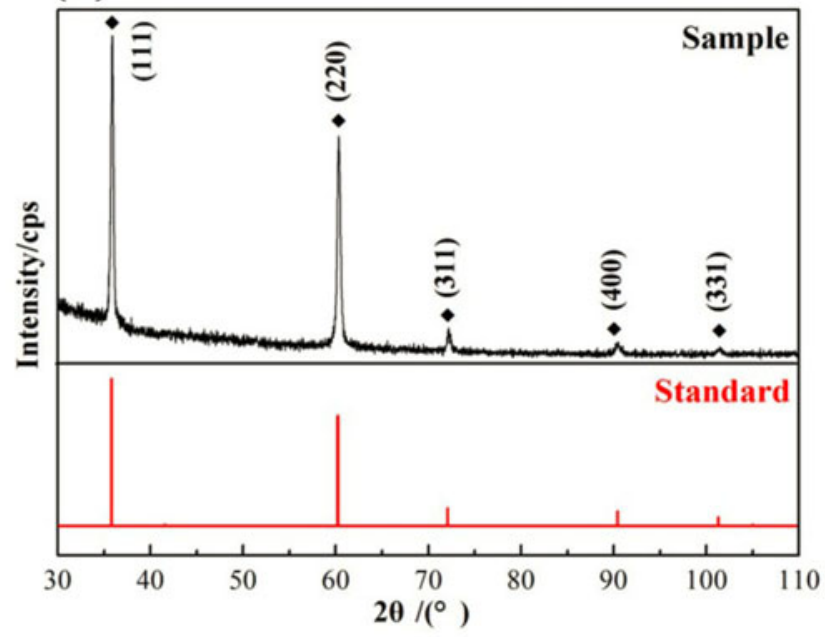

Figure 4. (a) High-resolution TEM image and corresponding FFT pattern (inset upper right) for film deposited at room temperature, (b) typical XRD pattern of films with in situ annealing.

\subsubsection{Property characterization}

One of the key factors for the ICF target is the surface finish, which usually gets worser as the thickness of the Be films increases. Thus, the relation between the surface finish and film thickness is critical for ICF applications, and needs to be investigated.

The influence of thickness on morphologies and roughness in $\mathrm{Be}_{2} \mathrm{C}$ film was studied by SEM and atomic force microscope (AFM). Figures 5(a) and (b) show the surface morphologies of films with thickness of 530 and $2300 \mathrm{~nm}$, respectively. Both of them exhibit very similar morphology that many small spherical-shaped granules homogeneously distribute over the surfaces. The corresponding surface roughnesses (RMS) for films with thickness of 530 and $2300 \mathrm{~nm}$ are 2.63 and $3.23 \mathrm{~nm}$, respectively. Similar surface morphology and roughness indicate that the surface finish of $\mathrm{Be}_{2} \mathrm{C}$ films is not sensitive to the thickness. Figures 5(a1) and (b1) are the cross-sectional morphologies of $\mathrm{Be}_{2} \mathrm{C}$ films measured by SEM. The cross-sectional morphologies reveal the uniform microstructure (without columnar crystal) of $\mathrm{Be}_{2} \mathrm{C}$ films, which is conducive to improving the symmetry of the ablation in ICF.

Based on the mass gain and thickness measured by SEM, the density and deposition rate of $\mathrm{Be}_{2} \mathrm{C}$ coatings were studied. The results revealed: the density of the deposited coatings reached $\sim 2.2 \mathrm{~g} / \mathrm{cm}^{3}$, which fully embodied the high density advantages of $\mathrm{Be}_{2} \mathrm{C}$ coatings with respect to beryllium and hydrocarbons; the deposition rate of DC reactive magnetron sputtering reached $\sim 300 \mathrm{~nm} / \mathrm{h}$, which showed the obvious advantage over RF sputtering $(<56 \mathrm{~nm} / \mathrm{h})^{[22]}$.

As ICF capsule materials, optical transparency is another advantage of $\mathrm{Be}_{2} \mathrm{C}$ over $\mathrm{Be}$ coatings. Figure 6 shows the typical optical transmittance spectra of the $\mathrm{Be}_{2} \mathrm{C}$ films and corresponding photograph. It reveals that $\mathrm{Be}_{2} \mathrm{C}$ coatings are transparent yellow-brown with sufficient $(\sim 40 \%)$ transmittance in the visible region and higher transmittance in the near infrared region (80\%). The optical transparent properties of $\mathrm{Be}_{2} \mathrm{C}$ make it possible to characterize the DT layers in $\mathrm{Be}_{2} \mathrm{C}$ capsules by optical methods and homogenized by infrared heating.

\section{High-purity Be materials}

\subsection{Purification principle}

Most purification methods separate the impurity by some difference of physical or chemical property between metal and impurity, such as the saturated vapor pressure, evaporation rate, melting point, as well as solubility difference between liquid phase and solid phase. Here, the pyrolysis method of the organometallic $\mathrm{Be}$ is used to generate the high-purity $\mathrm{Be}$ materials ${ }^{[41]}$. At first, the $\mathrm{Be}$ raw material ( $98.5 \mathrm{wt} \%$ ) is chloridized to produce the $\mathrm{BeCl}_{2}$. Afterward, the $\mathrm{BeCl}_{2} \cdot 2 \mathrm{Et}_{2} \mathrm{O}$ reacts with the t-butyl Grignard reagent to produce di-t-butylberyllium etherate, whose purity can reach at $99.999 \mathrm{wt} \%$ by the distillation. Finally, the high-purity dit-butylberyllium etherate (provided by Nanjing University) is pyrolyzed to form high-purity Be.

\subsection{Progress on high-purity Be materials}

The high-purity Be powder was prepared by the pyrolysis method. Figure 7 shows the SEM image of the compressed Be powder. The powder particle looks nearly spherical from SEM images, and its average diameter is about $1 \mu \mathrm{m}$. 

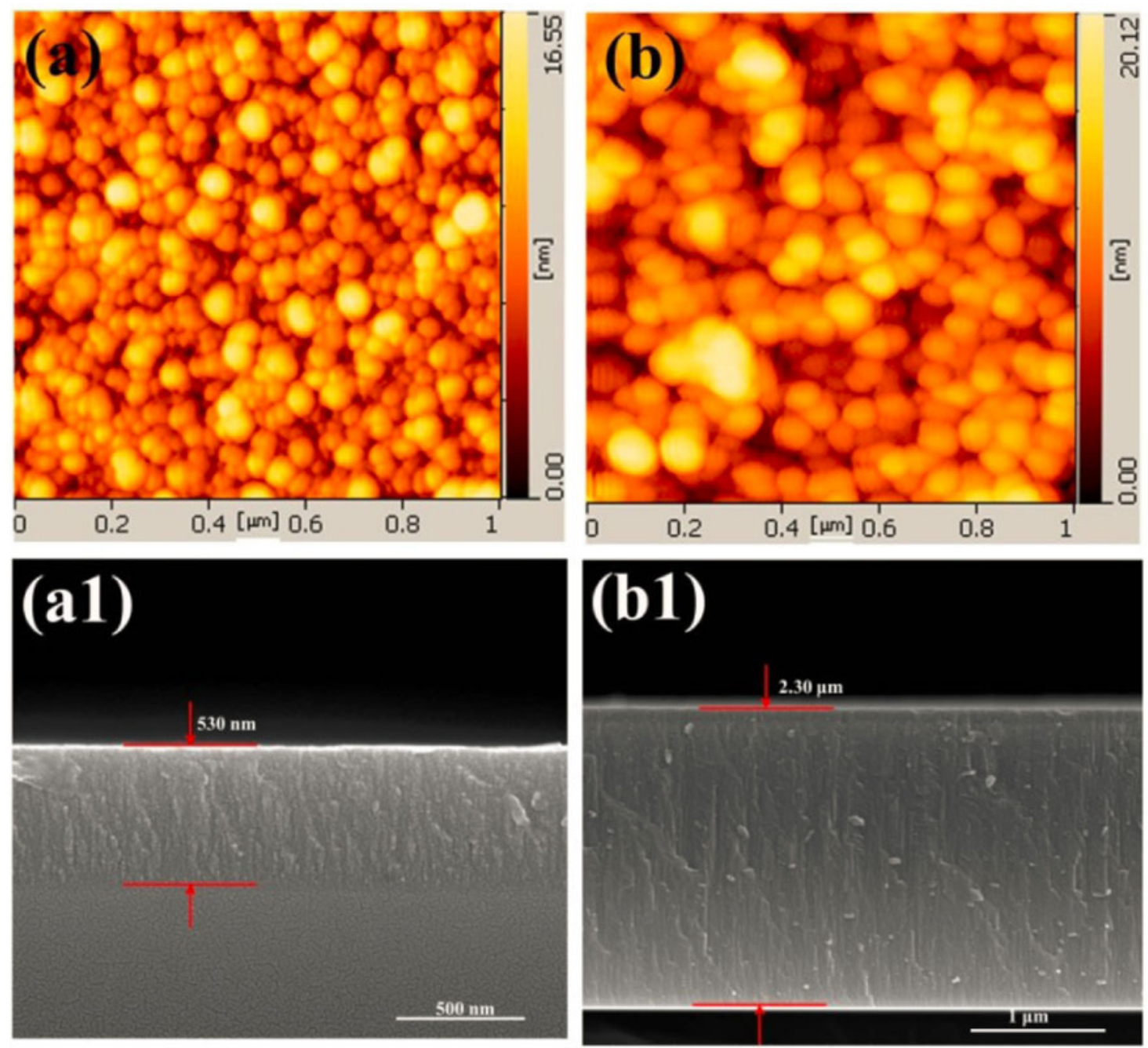

Figure 5. Typical surface and cross-sectional morphologies of $\mathrm{Be}_{2} \mathrm{C}$ films with different thickness: (a) and (b) surface morphologies by AFM, (a1) and (b1) cross-sectional morphologies by SEM.

The chemical compositions and impurity level in Be block were determined by a high-resolution ICP-MS (ppb) and ICP atomic emission spectrometry (AES) (ppm) after the sample was chemically digested with high-purity water and high-purity acid. The ultimate analysis results are needed to subtract the background value from the blank experiment, which was a complete ICP characterization except for adding Be powder into acids. In an ICP guide determination, the whole spectrum of Be powder was scanned first, and then nine impurities were quantitatively determined. Table 1 lists the content of $\mathrm{Al}, \mathrm{Fe}, \mathrm{Mn}, \mathrm{Ni}, \mathrm{Cr}, \mathrm{Ga}, \mathrm{Co}, \mathrm{Mo}, \mathrm{Sb}, \mathrm{O}$ and $\mathrm{C}$, etc.

The total content of the nine metal impurities is $61 \mathrm{ppm}$, and mainly includes the two major impurities, the $\mathrm{Al}$ of $34.7 \mathrm{ppm}$ and $\mathrm{Fe}$ of $23.8 \mathrm{ppm}$. In the process of $\mathrm{Be}$ purification, the dodecane was only used as a solvent. The impurity in the solvent was also determined by ICP-MS and ICP-AES. The results show that there exists no impurity in
Table 1. The content of impurities in Be powder.

\begin{tabular}{lll}
\hline Impurities & Content & Characterization methods \\
\hline $\mathrm{Al}$ & $34.7 \mathrm{ppm}$ & ICP-AES \\
$\mathrm{Fe}$ & $23.8 \mathrm{ppm}$ & ICP-AES \\
$\mathrm{Mn}$ & $0.045 \mathrm{ppm}$ & ICP-MS \\
$\mathrm{Ni}$ & $0.33 \mathrm{ppm}$ & ICP-MS \\
$\mathrm{Cr}$ & $0.9 \mathrm{ppm}$ & ICP-MS \\
$\mathrm{Ga}$ & $0.25 \mathrm{ppm}$ & ICP-MS \\
$\mathrm{Co}$ & $0.41 \mathrm{ppm}$ & ICP-MS \\
$\mathrm{Mo}$ & $0.32 \mathrm{ppm}$ & ICP-MS \\
$\mathrm{Sb}$ & $0.048 \mathrm{ppm}$ & ICP-MS \\
$\mathrm{O}$ & 0.82 at. $\%$ & LECO \\
$\mathrm{C}$ & 2.22 at. $\%$ & LECO \\
\hline
\end{tabular}

the dodecane. It can be plausibly deduced that the impurities in the Be powder are mostly from the raw materials of di-t-butylberyllium etherate. Both $\mathrm{C}$ and $\mathrm{O}$ contents are 


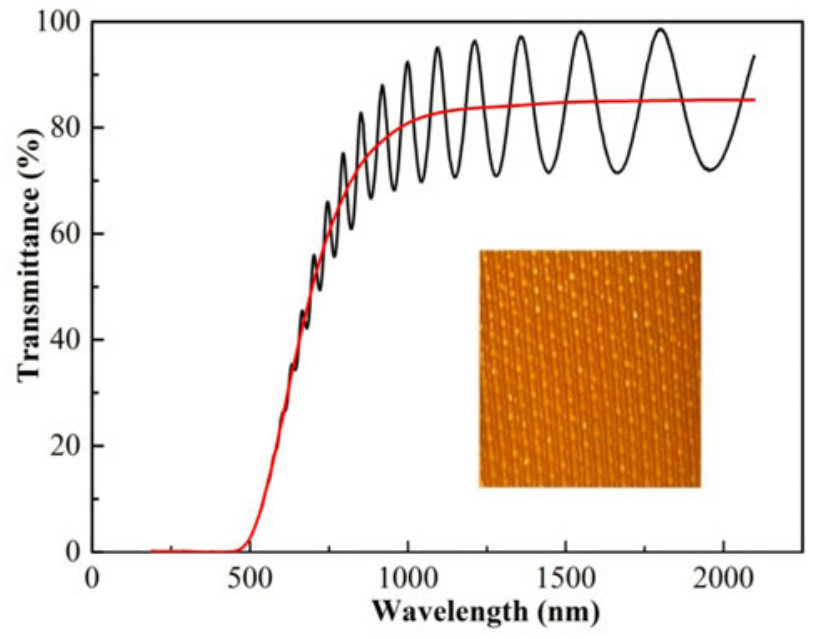

Figure 6. Typical optical transmittance spectra of the $\mathrm{Be}_{2} \mathrm{C}$ films and corresponding photograph (inset).

determined by LECO. There is a high content for $\mathrm{C}$ and $\mathrm{O}, 0.82$ at.\% $\mathrm{O}$ and 2.22 at.\% C. The $\mathrm{C}$ results from the alkylberyllium produced by incomplete pyrolysis of dit-butylberyllium etherate, and its content depends on the pyrolysis temperature ${ }^{[40]}$. The $\mathrm{O}$ in the Be powder is attributed to oxidation upon exposure of the Be powder in air during the storage and measurement.

\section{Conclusions}

The Be-based materials, such as $\mathrm{Be}-\mathrm{Cu}$ capsule, $\mathrm{Be}_{2} \mathrm{C}$, and high-purity $\mathrm{Be}$ material, have been investigated. The $\mathrm{Be}-$ $\mathrm{Cu}$ capsule with $1.2 \mathrm{~mm}$ diameter, RMS roughness $85 \mathrm{~nm}$, average deviation of wall thickness $\pm 1.5 \mu \mathrm{m}$, the $\mathrm{Cu}$ dopant in the concentration range of 0.6 at. $\%-0.96$ at. $\%$ and total shell thickness of $80 \mu \mathrm{m}$ has been fabricated. For strong anisotropic Be coating, a new active hydrogen reaction method can refine the $\mathrm{Be}$ grain size to $45 \mathrm{~nm}$. $\mathrm{Be}_{2} \mathrm{C}$ films were first deposited by DC reactive sputtering with a high deposition rate of $300 \mathrm{~nm} \mathrm{~h}^{-1}$. The compositions of the films mainly affected by the $\mathrm{CH}_{4}-\mathrm{Ar}$ ratios and sputtering power, and substrate temperature influenced the crystallinity. The properties of the pure polycrystalline $\mathrm{Be}_{2} \mathrm{C}$ films were characterized, which showed uniform microstructure, smooth surface, high density and good optical transparency. In addition, a particular purification technology for Be materials by pyrolysis of di-t-butylberyllium etherate has been reported in our work. The total content of metal impurities was $61 \mathrm{ppm}$ by ICP-MS determination, including the two major impurities, the $\mathrm{Al}$ of $34.7 \mathrm{ppm}$ and $\mathrm{Fe}$ of $23.8 \mathrm{ppm}$. The total $\mathrm{C}$ and $\mathrm{O}$ contents determined by LECO were 2.22 at. $\%$ and 0.82 at.\%, respectively.

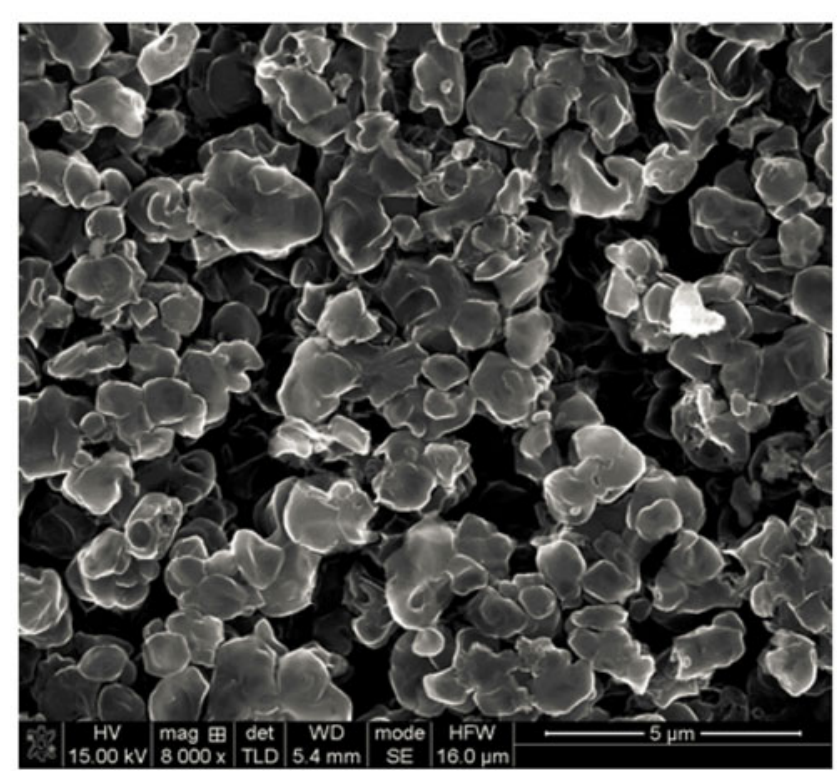

Figure 7. SEM micrograph of compressed Be powders.

\section{Acknowledgements}

This project was supported by the National Natural Science Foundation of China (11204280) and Laboratory of Precision Manufacturing Technology, CAEP (ZZ15011). The authors are grateful to Mr. Zhan-Wen Zhang, Mrs Su-Fen Chen for their PAMS mandrel, Mr Xiao-Jun Ma, Qi Wang, Yong Zeng for their measurement work, and Professor Yi Pan, Dr. Jian-Lin Han (Nanjing University) for their highpurity organometallic Be materials.

\section{References}

1. D. C. Wilson, A. N. Simakov, S. Yi, J. L. Kline, J. Salmonson, D. Clark, J. Milovich, M. Marinak, and D. Callahan, in Conference: Ignition Strategic Review LA-UR-13-25977 (2013).

2. A. N. Simaov, D. C. Wilson, S. A. Yi, J. L. Kline, D. S. Clark, J. L. Milovich, J. D. Salmonson, and S. H. Batha, Phys. Plasmas 21, 022701 (2014).

3. K. A. Moreno, H. W. Xu, A. Nikroo, H. Huang, J. Fong, J. E. Knipping, J. L. Kaae, and E. M. Giraldez, Fusion Sci. Technol. 51, 581 (2007).

4. M. M. Marinak, S. G. Glendinning, R. J. E. Wallac, B. A. Remington, S. V. Weber, S. W. Hann, and G. W. Collins, Phys. Plasmas 9, 3567 (2002).

5. C. L. Guerrero and J. M. Perlado, J. Phys.: Conf. Ser. 688, 012022 (2016).

6. C. Wang, Z. Li, D.-F. Li, and Z. Ping, Phys. Plasmas 22, 102702 (2015).

7. M. Mehine, C. Björkas, K. Vörtler, K. Nordlund, and M. I. Airilaet, J. Nucl. Mater. 414, 1 (2011).

8. R. Mateus, P. A. Carvalho, N. Franco, L. C. Alves, M. Fonseca, C. Porosnicu, and E. Alves, J. Nucl. Mater. 442, S320 (2013).

9. H. Xu, A. Nikroo, J. R. Wall, R. Doerner, M. Baldwin, and J. H. Yu, Fusion Sci. Technol. 49, 778 (2007). 
10. H. Xu, C. Alford, E. Chason, A. J. Detor, T. Fuller, A. V. Hamza, J. Hayes, K. A. Moreno, A. Nikroo, T. van Buuren, Y. Wang, J. Wu, H. Wilkens, and K. P. Youngblood, J. Mater. Res. 378, 1 (2011).

11. D. C. Wilson, P. A. Bradley, N. M. Hoffman, F. J. Swenson, D. P. Smitherman, R. E. Chrien, R. W. Margevicius, D. J. Thoma, L. R. Foreman, J. K. Hoffer, S. R. Goldman, S. E. Caldwell, T. R. Dittrich, S. W. Haan, M. M. Marinak, S. M. Pollaine, and J. J. Sanchez, Phys. Plasmas 5, 1953 (1998).

12. B. C. Luo, K. Li, X. L. Kang, J. Q. Zhang, Y. D. He, J. S. Luo, W. D. Wu, and Y. J. Tang, Chin. Phys. B 23, 066804 (2014).

13. B. C. Luo, K. Li, X. L. Tan, J. Q. Zhang, J. S. Luo, X. D. Jiang, W. D. Wu, and Y. J. Tang, J. Alloys Compd. 607, 150 (2014).

14. B. C. Luo, K. Li, J. Q. Zhang, J. S. Luo, W. D. Wu, and Y. J. Tang, J. Korean Phys. Soc. 68, 557 (2016).

15. B. C. Luo, J. S. Luo, K. Li, J. Q. Zhang, W. D. Wu, and Y. J. Tang, Rare Metal Mater. Eng. 41, 1684 (2012).

16. R. Brusasco, S. Letts, P. Miller, M. Saculla, and R. Cook, J. Vac. Sci. Technol. A 14, 1019 (1996).

17. W. S. Shih, R. B. Stephens, and W. J. James, Fusion Sci. Technol. 37, 24 (2000).

18. S. Laref and A. Laref, Comput. Mater. Sci. 44, 664 (2008).

19. M. W. Mallett, E. A. Durbin, M. C. Udy, D. A. Vaughan, and E. J. Center, J. Electrochem. Soc. 101, 298 (1954).

20. Y. X. Xie, R. B. Stephens, N. C. Morosoff, and W. J. James, J. Fusion Energy 17, 259 (1998).

21. W. S. Shih, N. E. Barr, W. J. James, N. C. Morosoff, and R. B. Stephens, Fusion Sci. Technol. 31, 442 (1997).

22. Y. X. Xie, Plasma Deposition of Beryllium Carbide via Magnetron Sputtering (University of Missouri, 1998).

23. Y. D. He, J. S. Luo, J. Li, L. B. Meng, B. C. Luo, J. Q. Zhang, Y. Zeng, and W. D. Wu, Fusion Eng. Des. 103, 118 (2016).

24. Y. D. He, J. S. Luo, K. Li, B. C. Luo, J. Q. Zhang, H. B. Yin, and W. D. Wu, RSC Adv. 6, 39444 (2016).

25. S. W. Haan, P. A. Amendt, and D. A. Callahan, Fusion Sci. Technol. 51, 509 (2007).

26. S. W. Haan, J. D. Salmonson, D. S. Clark, D. D. Ho, B. A. Hammel, D. A. Callahan, C. J. Cerjan, M. J. Edwards, S. P. Hatchett, O. L. Landen, J. D. Lindl, B. J. MacGowan, M. M.
Marinak, D. H. Munro, H. F. Robey, B. K. Spears, L. J. Suter, R. P. Town, S. V. Weber, and D. C. Wilson, Fusion Sci. Technol. 59, 1 (2011).

27. S. H. Goods and D. E. Dombrowski, in Conference: 3. IEA International Workshop on Beryllium Technology for Fusion AC04-94AL85000 (1997).

28. E. G. Creutz and D. Gurinsky, Met. Progr. 62, 82 (1952).

29. A. R. Kaufmann, P. Grodon, and D. W. Lillie, Trans. Am. Soc. Met. 42, 786 (1950).

30. S. W. Haan, M. C. Herrmann, and P. A. Amendt, Fusion Sci. Technol. 49, 553 (2006).

31. L. E. Tanner and H. Okamoto, Bulletin Alloy Phase Diagrams 9, 563 (1988).

32. M. McElfresh, J. Gunther, C. Alford, E. Fought, and R. Cook, Fusion Sci. Technol. 49, 786 (2006).

33. D. S. Montgomery, A. Nobile, and P. J. Walsh, Rev. Sci. Instrum. 75, 3986 (2004).

34. D. A. Davydov, O. V. Kholopova, and B. N. Kolbasov, J. Nucl. Mater. 367, 1079 (2007).

35. D. C. Swift, T. E. Tierney, S. N. Luo, D. L. Paisley, G. A. Kyrala, A. Hauer, S. R. Greenfield, A. C. Koskelo, K. J. Mcclellan, H. E. Lorenzana, D. Kalant, B. A. Remington, P. Peralta, and E. Loomis, Phys. Plasmas 12, 056308 (2005).

36. K. Kádas, L. Vitos, B. Johansson, and J. Kollar, Phys. Rev. B 75, 035132 (2007).

37. A. Nikroo, K. C. Chen, M. L. Hoppe, H. Huang, J. R. Wall, H. Xu., M. W. McElfresh, C. S. Alford, R. C. Cook, J. C. Cooley, R. Fields, R. Hackenberg, R. P. Doerner, and M. Baldwin, Phys. Plasmas 13, 056302 (2006).

38. J. Q. Zhang, J. S. Luo, B. C. Luo, and W. D. Wu, High Power Laser Part. Beams 23, 1277 (2011).

39. J. Q. Zhang, J. S. Luo, B. C. Luo, and W. D. Wu, Rare Metal Mater. Eng. 41, 1483 (2012).

40. Powder Diffraction File (PCPDFWIN v.2.02), (JCPDS International Centre for Diffraction Data, 33-0191, 1999).

41. R. Baker, G. Brendel, B. Lowrance, J. Mangham, E. Marlett, and L. Shepherd, J. Organomet. Chem. 159, 123 (1978). 